\title{
REPERCUSSÕES NA COMUNICAÇÃO, INTERAÇÃO E PARTICIPAÇÃO SOCIAL DA PESSOA COM ESCLEROSE LATERAL AMIOTRÓFICA (ELA) NA PERSPECTIVA DE FAMILIARES OU CUIDADORES
}

\section{Thais Cristina Leite de Novais*, Lavoisier Leite Neto, Regina Yu Shon Chun}

\section{Resumo}

A Esclerose Lateral Amiotrófica (ELA), doença neurodegenerativa, provoca alterações motoras, tornando a pessoa dependente de terceiros à medida que a doença progride ${ }^{1}$. Diante das limitações de comunicação, a implementação de sistemas alternativos de comunicação pode favorecer a linguagem, interação e participação social ${ }^{2}$. O cuidador/familiar ocupa espaço central, adaptando sua rotina às necessidades de quem cuida ${ }^{3}$. O objetivo foi investigar repercussões da ELA na comunicação e interação para a pessoa e o impacto do cuidado na percepção dos familiares e/ou cuidadores. Há repercusssões na comunicação e interação para a pessoa e seu familiar ou cuidador.

\section{Palavras-chave:}

Esclerose Lateral Amiotrófica, Família, Barreiras de Comunicação.

\section{Método}

- Estudo de corte transversal de abordagem qualitativa; vinculado à pesquisa "Associação entre vulnerabilidade comunicativa e alterações estruturais e funcionais cerebrais em pacientes com Esclerose Lateral Amiotrófica", aprovada pelo CEP da UNICAMP sob n CAAE 62912416.4.0000.5404.

- Amostra de 17 participantes, familiar e/ou cuidador de pessoas com ELA em acompanhamento no Ambulatório de Doenças Neuromusculares do Hospital das Clínicas da FCM/UNICAMP.

- Coleta realizada pelo pesquisador principal, por meio de entrevistas com perguntas abertas, posteriormente, transcritas e analisadas.

\section{Resultados e Discussão}

Tabela 1. Caracterização da amostra por idade, sexo, tempo de cuidado e relação de cuidado

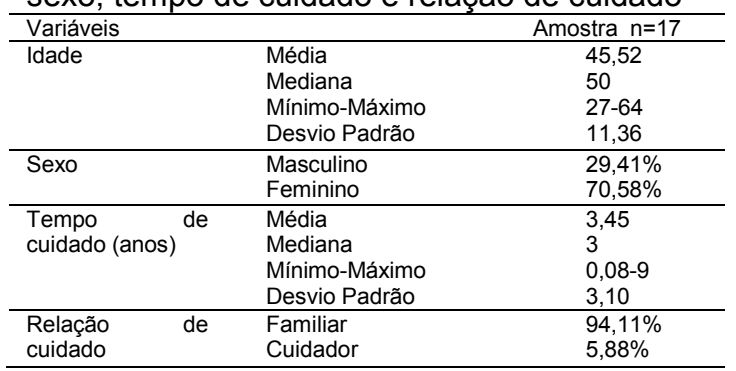

A média de idade dos cuidadores encontrada nesta pesquisa ficou abaixo de estudos anteriores ${ }^{4}$, com maior frequência de cônjuges e filhos. Em relação à sexo ${ }^{3}$ e relação de cuidado $^{5}$, os achados corroboram os dados encontrados na literatura científica, que referem um maior número de cuidadoras mulheres e em sua grande maioria familiares. No tocante ao tempo de cuidado, observa -se média de 3,45 anos, tendo este sido desde o aparecimento dos primeiros sintomas. A sobrecarga emocional (Gráfico 1) decorre da responsabilidade do cuidado, falta de informação sobre a ELA e de preparo para cuidar bem como pela condição de saúde em que a pessoa com ELA se encontra ${ }^{5}$. Apesar de ser um recurso facilitador da comunicação², poucos fazem uso de CSA. A baixa adesão à terapia relaciona-se à dificuldade de acesso $^{6}$ (Gráfico 2).
Gráfico 1. Distribuição das respostas quanto a dificuldades do cuidador

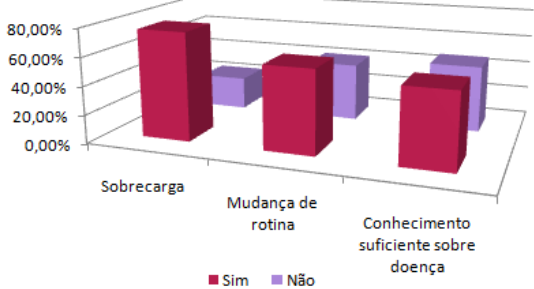

Gráfico 2. Distribuição das respostas quanto à comunicação, uso da CSA e atendimento

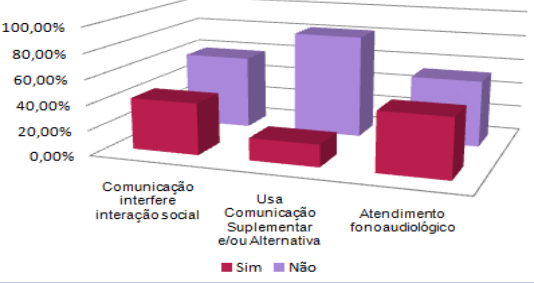

Conclusão

As alterações de comunicação interferem na interação social e na dinâmica de vida para e pessoa com ELA e seu familiar ou cuidador. O cuidado gera sobrecarga emocional e outras repercussões para ambos. Há baixa adesão à terapia fonoaudiológica e ao uso da CSA.

\section{Agradecimentos e Referências}

Agradecimentos ao $\mathrm{PIBIC/CNPq}$ pelo auxílio à pesquisa.

\footnotetext{
${ }^{1}$ Larsson, B. J.; Fröjd, C.; Nordin, K.; Nygren, I. Relatives of patients with amyotrophic lateral sclerosis: Their experience of care and support. Palliative and Supportive Care. 2015, v. 13, n. 06, p.1569-1577.

${ }^{2}$ Mckelvey, M.; Evans, D.; Kawai, N.; Beukelman, D. Communication Styles of Persons with ALS as Recounted by Surviving Partners. Augmentative and Alternative Communication, 2012, v. 28, n. 4, p.232-242.

${ }^{3}$ Girardi-paskulin, LM et al. Sintomas depressivos de idosos e sobrecarga de cuidadores em atenção domiciliar. Invest. educ. enferm. 2017, 35(2): 210-220.

${ }^{4}$ Burke et al. Caregiver burden in amyotrophic lateral sclerosis: a cross-sectional investigation of predictors. J Neurol. 2015, v. 262, p. 15261532.

${ }^{5}$ Souza, L.R. et al. Sobrecarga no cuidado, estresse e impacto na qualidade de vida de cuidadores domiciliares assistidos na atenção básica. Cad. Saúde Colet. 2015, v. 23, n.2, p. 140-149

${ }^{6}$ Miranda G.M.D. et al. Assistência Fonoaudiológica no SUS: A Ampliação do acesso e o desafio de superação das desigualdades. Revista CEFAC. 2015, v. 17.
} 